\title{
Abdominal VASER LipoSelection Avoiding Abdominoplasty
}

\author{
Munir Alam* \\ Department of Plastic Surgery, Consultant Plastic Surgeon, Faisal Hospital, Pakistan
}

Received: June 16, 2018; Published: June 22, 2018

*Corresponding author: Munir Allam, Department of Plastic Surgery, Int/European Board of Cosmetic Surgery, Consultant Plastic Surgeon, Faisal Hospital, 46 University Town, Millat Road, Faisalabad, Pakistan

\begin{abstract}
The surgical techniques described for each of four patient categories of abdominolipoplasty are: type I-Liposuction alone, type II-miniabdominoplasty, infra umbilical plication + Liposuction, type III-modified abdominoplasty, plication above and below umbilicus + Liposuction and type IV-standard abdominoplasty + sheath plication + Liposuction [1]. Historically, the treatment of protuberant abdomen was major surgical procedure which often require multiple operations under general anesthesia with its risks like bleeding, hematoma/seroma, long scar and infections etc. The old-style liposuction was first used in early 1970s for type I or as a combination procedure with surgery. With the advancement in the techniques of minimal invasive surgery and modern equipment, liposuction is now a routine procedure in all the types with minimal risks by using VASER Liposelection technique [2]. I describe my personal experience with abdominal VASER Liposelection in eighty-seven patients of Type I-IV during four years from March 2009 to March 2013, avoiding abdominoplasty. This ambulatory technique is a low risk procedure, performed under local anesthetic (tumescent technique), minimum or no scar, high satisfaction level, effective in all the categories of protuberant abdomen and helps in psychological improvement.red algae, brown algae.
\end{abstract}

Keywords: VASER; Abdominoplasty; Liposuction; Tummy Tuck

\section{Introduction}

Abdominoplasty is a major surgical procedure associated with a variety of early and late complications [3] Abdominal wall consist of three layers, innermost layer is made of muscles, middle layer is made of fat and outer layer is made of skin. Huger and Nahai described the three zones of blood supply to the anterior abdominal wall $[4,5]$. The patient should be thoroughly evaluated for excess fat, skin tone, muscle laxity, abdominal wall scars and hernias. The aesthetic and anatomic considerations are slightly different in males and female. The abdominal wall fat is well compartmentalized into three layers by Scarpa's and Camper's fascia. In most instances the superficial fat layer is preserved during treatment of both males and females for smooth contouring of the abdominal wall surface.

Traditional liposuction has dramatically reduced the need for excisional body contouring techniques, especially in the abdomen. Prior to liposuction, invariably clients had to accept long abdominal scars if they expected significant improvements in body contouring. The suction assisted liposuction (SAL) has not satisfactorily addressed the needs of clients with redundant infraumbilical fat and excess skin and has produced inconsistent results in the supraumbilical area [6]. The VASER liposelection initiate the collagen remodeling of loose skin and deeper tissues resulting in shrinkage of skin which quite often takes three months post operatively $[7,8]$.

\section{Discussion}

The VASER is a "Vibration Amplification of Sound Energy at Resonance". The VASER Liposelection system is a fourth generation of ultrasonic technology which solely target the adipocytes uses an advanced, patented fat removal technology without damaging the surrounding structures like blood vessels, nerves and collagen bundles. The results showed near complete elimination of adverse events and better overall results. It is called "Liposelection" because the vibration energy of the sound waves interacts with the fat cells and has no harmful effects on blood vessels or the connective tissue bands though helps to contract the lax abdominal skin. The VASER Lipo system spares the tissue matrix, removing primarily the fatty component, producing smooth, predictable results i.e; Sculpting the tissue (Figures 1-9).

During assessment of abdominal wall, if the protuberance of abdomen found to be due to abdominal muscle laxity, patient treatment with VASER Liposelection may not improve. The author advice to the client is abdominal muscle strengthening exercises (Pilates) for three months prior to VASER Liposelection. If abdominal muscle laxity not improved with exercise, then rectus plication may be necessary as an adjunct procedure with VASER Liposelection [9]. I prefer to perform the three stages of the VASER Liposelection procedure; infiltration of tumescent fluid [10], VASE Ring and 
aspiration through $3 \mathrm{~mm}$ three stab incision (Figure 1). Manual lymphatic message is started after 3 days post operatively twice a day for 15-20 minutes and customized compression garments are used most of the time especially night time for three months. VASER
Liposelection if combined with Abdominoplasty may result in skin necrosis and delayed healing if patient is morbidly obese and heavy smokers and preexisting scars [11].

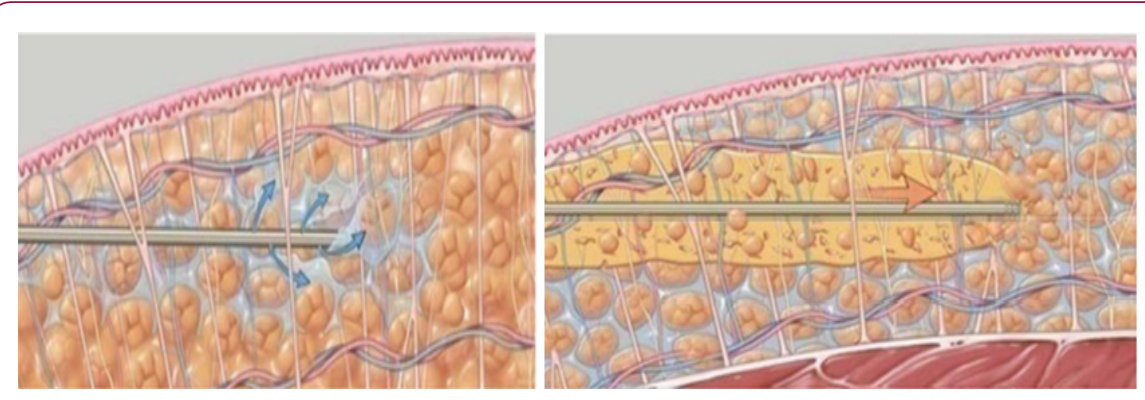

Figures 1-3: Tissue Selectivity.
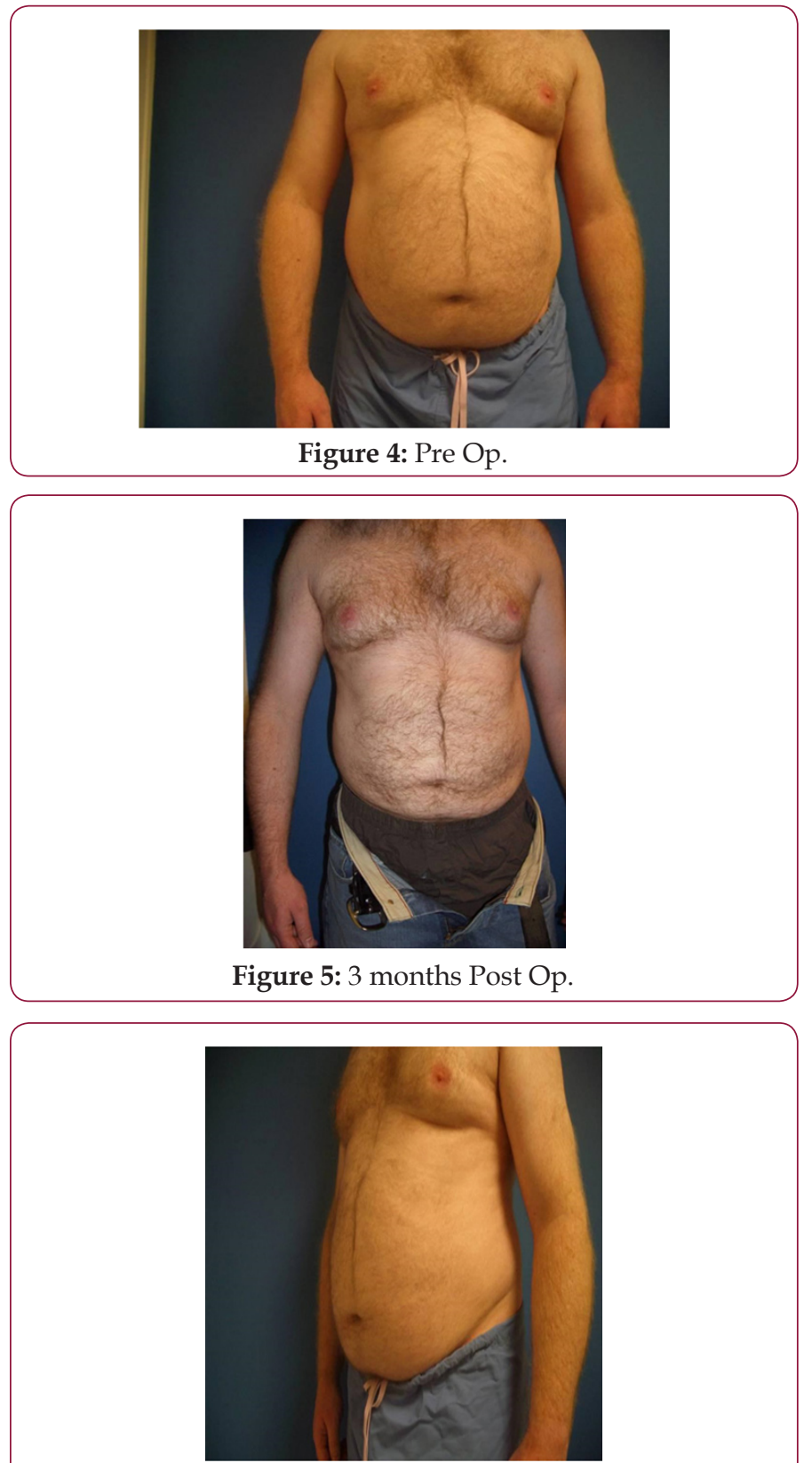

Figure 6: Pre Op.
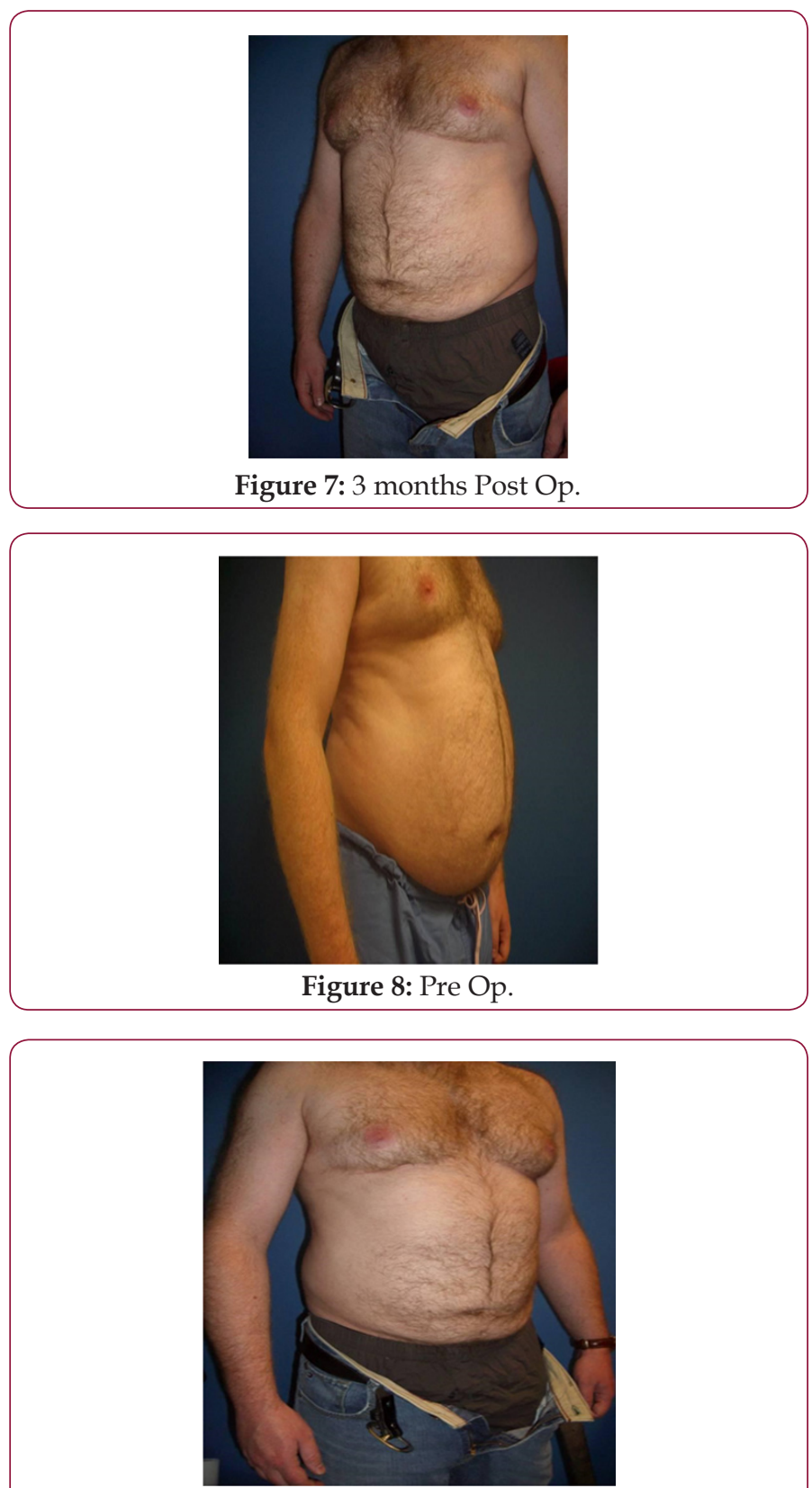

Figure 9: 3 months Post Op. 


\section{Conclusion}

With my wide range experience of abdominal VASER Liposelection, I recommend this ambulatory low risk procedure performed under local anesthetic with high satisfaction level for all patient categories of Matarasso classification. However, this technique does not improve the abdominal muscle laxity.

\section{References}

1. Matarasso A (1991) Abdominolipoplasty: A system of classfication and treatment for combined abdominoplasty and suction-assisted lipectomy. Aesth Plast Surg 15(1): 111.

2. Alam M, Anwar M (2016) Skin shrinkage in Gynaecomastia with VASER Liposelection. Pakistan Journal of Plastic Surgery 4(3): 14-18.

3. Matarasso A (1997) Awareness and Avoidance of Abdominoplasty Complications. Aesthetic Surgery Journal 17(4): 256-261.

4. Huger WE (1979) The anatomic rationale for abdominal lipectomy. Am Surg 45 (9): 612-617.

(C) (i) This work is licensed under Creative

Submission Link: https://biomedres.us/submit-manuscript.php
5. Nahai F, Brown GR (1976) Vasconez LO Blood supply to the abdominal wall as related to planning abdominal incisions. Am Surg 42(9): 691695.

6. Rohrich RJ, Beran JS, Kenkel JM (1998) Ultrasonic assisted liposuction. Quality medical publishing, Inc, St Louis, Missouri, US, pp. 196.

7. Alam M (2016) Role of Liposelection in the treatment of Gynaecomastia and new clinical classification. Pakistan Journal of Plastic Surgery 4(1).

8. Zocchi M (1992) Ultrasonic liposculpturing. Aesthetic Plast Surg 16(4): 287-298.

9. Yousif (2004) Transverse Rectus Sheath Plication in Abdominoplasty, Plastic and Reconstructive Surgery September $1^{\text {st }} 114(3)$ : 778-784

10. Klein JA (2000) Pharmacology of lidocaine. In Tumescent Technique, Tumescent Anesthesia and Microcannular Liposuction. Mo: Mosby, Inc Chap, St Louis, US, p.17.

11. El Khatib HA, Bener A (2004) Abdominal Dermolipectomy in an Abdomen with Pre-Existing Scars. A different concept 114(4): 992-997.

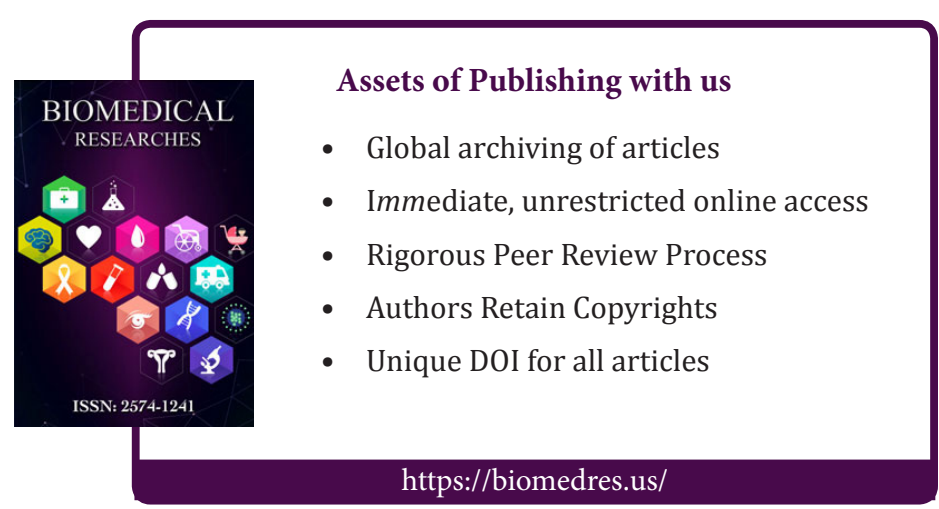

